\title{
INVESTIMENTOS ESTRANGEIROS \\ NOS SISTEMAS FINANCEIROS \\ LATINO-AMERICANOS: \\ OS CASOS DA ARGENTINA, DO BRASIL E DO MÉXICO*
}

\section{Maria Cristina Penido de Freitas ${ }^{* *}$}

\author{
Daniela Magalhães Prates ${ }^{* * *}$
}

\begin{abstract}
RESUMO Desde o retorno dos fluxos de capitais voluntários para a América Latina nos anos 1990 ocorreu a intensificação dos investimentos estrangeiros nos mercados financeiros locais, os quais assumiram, notadamente, as formas de fluxos de portfólio e de investimento direto mediante a aquisição de participação acionária nas instituições financeiras domésticas. Argentina, Brasil e México foram os três países que mais absorveram esses fluxos destinados à região. O objetivo deste artigo é analisar os efeitos desses investimentos sobre os sistemas financeiros domésticos desses três países latino-americanos, que, longe de serem homogêneos, se diferenciaram em função do grau de abertura financeira e da gestão macroeconômica.
\end{abstract}

Palavras-chave: globalização financeira; mercados financeiros latino-americanos; fluxos de portfólio; investimentos diretos estrangeiros

Código JEL: F32, F36, 016, 054

\footnotetext{
* Artigo recebido em 28 de maio de 2007 e aprovado em 3 de junho de 2008. As autoras agradecem as sugestões e recomendações do parecerista anônimo, se responsabilizando, como de praxe, pelos erros e omissões.

** Doutora em Ciências Econômicas pela Universidade de Paris XIII - França e professora da PUC-SP, e-mail: crispenido@uol.com.br

*** Professora-doutora do Instituto de Economia da Universidade de Campinas (Unicamp), pesquisadora do Centro de Estudos de Conjuntura e Política Econômica desse Instituto e pesquisadora do CNPq e da Fapesp, e-mail: daniprates@eco.unicamp.br
} 
FOREIGNER'S INVESTMENTS IN THE LATIN-AMERICAN FINANCIAL SYSTEMS: THE EXPERIENCES OF ARGENTINA, BRAZIL AND MEXICO

ABSTRACT In the 90's, the context of the renewal of capital flows to Latin America, the foreigner's investments in the local financial markets intensified not only as portfolio investments but as direct stock ownership of the financial enterprises. But, this movement is so far to be homogeneous since there are wide differences in the financial openness degrees and the macroeconomics policies across the countries. For this, we examine the effects of this process on the three Latin-American financial systems - the Brazilian, the Argentinean and Mexican ones - which have attracted the majority of the capital inflows to the region.

Key words: financial globalization; Latin-American financial markets; portfolio investment flows; direct investments 


\section{INTRODUÇÃO}

No contexto do retorno dos fluxos de capitais voluntários para a América Latina nos anos 1990, ocorreu a intensificação dos investimentos estrangeiros nos mercados financeiros locais, os quais assumiram, notadamente, as formas de fluxos de portfólio e de investimento direto mediante a aquisição de participação acionária nas instituições financeiras domésticas.

Brasil, México e Argentina absorveram a maior parte dos fluxos de capitais investidos na região a partir da consolidação da globalização financeira, entendida como um processo de eliminação das barreiras internas entre os diferentes segmentos dos mercados financeiros, somada à interpenetração dos mercados monetários e financeiros nacionais e sua integração aos mercados globalizados (Chesnais, 1996). Todavia, o ingresso de um volume excessivo de fluxos de portfólio, atraídos por oportunidades de ganhos financeiros de curto prazo, resultou, em um primeiro momento, na emergência de situações de fragilidade macroeconômica e financeira doméstica (Kregel, 1999) e, em um segundo momento, no colapso dos regimes de câmbio administrado (bandas cambiais nos dois primeiros países e regime de currency board na Argentina). Após as respectivas crises cambiais, esses regimes foram substituídos, nos três casos, por regimes de flutuação suja, com graus diferenciados de intervenção. ${ }^{1}$

Este artigo analisa os efeitos desses investimentos sobre os sistemas financeiros domésticos desses três países entre 1990 e 2007, procurando destacar as diferenças nos períodos que precederam e sucederam as respectivas crises cambiais. Esses efeitos se diferenciaram em função, sobretudo, de dois fatores: do grau de abertura financeira ${ }^{2}$ e da gestão macroeconômica doméstica, que constituem o pano de fundo da análise desenvolvida a seguir, mas não serão tratados aqui de forma detalhada.

A trajetória do processo de liberalização dos investimentos estrangeiros de portfólio estrangeiro (IEP), iniciado no final da década de 1980, foi bastante diferenciada na Argentina, no Brasil e no México. O grau de abertura financeira desses três países sofreu importantes modificações após as respectivas crises cambiais e a adoção dos regimes de câmbio flutuante. $\mathrm{Na}$ Argentina, onde a abertura financeira era total no período pré-crise, vários controles de capitais foram introduzidos após o colapso do regime de cur- 
rency board. Em contraste, México e, principalmente, Brasil, cuja integração financeira com o exterior era menos intensa no período pré-crise, ampliaram o acesso dos não-residentes aos seus respectivos mercados financeiros domésticos, apesar de ainda manterem restrições à conversibilidade interna da moeda nacional.

Esses países também apresentam traços distintos no que se refere ao tratamento legal conferido às instituições estrangeiras. Enquanto na Argentina essas instituições encontraram um ambiente regulatório mais favorável, pois desde 1977 vigorava o livre acesso ao sistema financeiro, no México e no Brasil as condições para o estabelecimento de filiais por não-residentes e para a participação no capital social de bancos locais eram muito restritivas no início da década de 1990. No caso mexicano, as restrições aos bancos estrangeiros foram sendo gradativamente flexibilizadas a partir de 1990 até a completa liberalização em 2005. Já no Brasil, o governo vem, desde 1995, fazendo uso de uma brecha legal na Constituição Federal em vigor para autorizar a ampliação da presença de instituições financeiras estrangeiras no país, sem submeter a matéria à apreciação do legislativo.

Os argumentos serão organizados da seguinte forma: após esta breve introdução, serão examinados as características e os efeitos sobre os mercados financeiros da Argentina, do Brasil e do México dos fluxos de portfólio (seção 1) e da expansão dos investimentos diretos estrangeiros sobre os sistemas financeiros nacionais (seção 2) no período 1990 a 2007. As conclusões serão apresentadas na seção 3 .

\section{OS IMPACTOS DOS INVESTIMENTOS ESTRANGEIROS DE PORTFÓLIO NOS MERCADOS FINANCEIROS LATINO-AMERICANOS}

Argentina, Brasil e México absorveram um grande volume de IEP após a implementação dos programas de estabilização com âncora cambial e abertura financeira a partir do final da década de 1980 e início da década de 1990, os quais viabilizaram sua inserção no processo de globalização financeira. Todavia, esses investimentos diferenciaram-se, de forma significativa, em relação ao seu perfil - investimentos em títulos de renda fixa versus ações. Moldadas pelo grau de abertura financeira, ao lado da gestão macroeconômica adotada, essas características condicionaram tanto os impactos 
desses fluxos sobre os respectivos mercados financeiros, cuja análise é o objetivo desta seção, como a modalidade e intensidade das crises cambiais que eclodiram após a reversão súbita desses fluxos (enquanto no México e na Argentina as crises foram gêmeas - cambiais e bancárias -, no Brasil ela se circunscreveu ao mercado de câmbio).

Os IEP implicam riscos financeiros consideráveis para os países periféricos, que permaneceram encobertos no período de abundância de recursos externos. A eclosão das crises gêmeas e/ou cambiais na segunda metade dos anos 1990 explicitou esses riscos e suscitou a elaboração de estudos acadêmicos e no âmbito dos organismos multilaterais, voltados para a compreensão dos seus determinantes. A partir de então, proliferaram artigos de economistas do mainstream e working papers e relatórios elaborados pelo staff desses organismos, destacando a natureza volátil e pró-cíclica dos fluxos de portfólio para os países "emergentes", bem como o descasamento de moedas nos balanços dos agentes econômicos provocado por esses fluxos (em função da denominação em moeda estrangeira dos títulos de dívida emitidos pelos residentes desses países nos mercados domésticos ou internacionais). Nesse contexto, novos termos surgiram no debate econômico para caracterizar a natureza volátil dos fluxos de capitais - como "on-off nature" (Adams, Mathieson e Schinasi, 1999; Mathieson e Schinasi, 2001), "sudden stops" (Calvo e Reinhart, 2000; Edwards, 2005), "feast and famine" (IMF, 2003) e "credit booms" (IMF, 2004) - ou se tornaram recorrentes, como "balance sheet effects" e "currency mismacht" (Goldstein e Turner, 2004; Eichengreen, Hausmann e Panizza, 2003 e 2005). ${ }^{3}$

Todavia, uma questão fundamental, nem sempre enfatizada na literatura, refere-se à relação entre esses riscos e as características dos investimentos de portfólio nos mercados financeiros domésticos. As experiências dos três países selecionados, analisadas nos próximos parágrafos, revelam que a natureza dos fluxos - sob a forma de investimentos em obrigações de renda fixa ou em ações, de capitais de curto ou de longo prazo - condiciona a capacidade de esses mercados neutralizarem os efeitos de uma súbita reversão dos recursos, associada seja a choques externos (como uma elevação dos juros nos países centrais), seja a mudanças nas expectativas dos investidores em relação à sustentabilidade da situação macroeconômica do país em questão (em função, por exemplo, dos elevados déficits em conta-corrente, 
da fragilidade dos sistemas financeiros e/ou da deterioração crescente das contas públicas etc.).

No caso da Argentina, os dados disponíveis atualmente, apesar de mais desagregados que os existentes durante a vigência do Regime de Conversibilidade, ${ }^{4}$ ainda são pouco desagregados e, assim, não permitem a quantificação precisa dos IEP no mercado financeiro local. Isso porque as informações divulgadas pelo FMI no International Financial Statistics, além de desatualizadas (o último dado é de 2006), referem-se aos investimentos de portfólio em ações e títulos de renda fixa emitidos por residentes na Argentina, tanto no mercado doméstico como no mercado financeiro internacional (no caso das ações, American Depositary Receipts - ADRs, e no caso dos papéis de renda fixa, bonds, notes e commercial papers). Já os dados do balanço de pagamentos da Argentina compilados pelo Banco Central da República Argentina (BCRA) são mais atualizados, mas disponíveis somente para o período mais recente (2003-2007), e dizem respeito ao total dos investimentos de portfólio de não-residentes no mercado, sem a abertura por tipo de aplicação (renda fixa e variável). As informações fornecidas pelas duas bases de dados foram consolidadas na tabela 1.1.

No primeiro subperíodo (1991-1998), predominaram os investimentos de portfólio em títulos de renda fixa, seja no mercado local, seja no mercado financeiro internacional. Tanto residentes quanto não-residentes utilizaram esses títulos para internalizar recursos na Argentina e usufruir as elevadas taxas de juros internas vigentes. Dado o regime de currency board vigente a partir do Plano de Conversibilidade, o efeito de um aumento das reservas de divisas é a expansão da oferta monetária e, conseqüentemente, da capacidade de empréstimo do sistema bancário (Blejer e Rozenwurcel, 1997; Dominguez e Tesar, 2005). Assim, o êxito do Plano dependeu, em grande medida, das novas condições vigentes nos mercados financeiros internacionais a partir do final da década de 1980, bem como da redução da taxa de juros dos Estados Unidos no início dos anos 1990. Essas condições, ao lado desse fator externo conjuntural, foram os principais determinantes do retorno dos fluxos de capitais voluntários para a América Latina e do êxito desse Plano e dos demais programas de estabilização com âncora cambial adotados na América Latina. 
Tabela 1.1: Os investimentos estrangeiros de portfólio em títulos argentinos (US\$ milhões)

\begin{tabular}{|c|c|c|c|c|c|c|c|}
\hline $\mathrm{d}$ & $\begin{array}{c}\text { IEP no } \\
\text { mercado } \\
\text { doméstico }\end{array}$ & Total & $\begin{array}{c}\text { IEP } \\
\text { ações }\end{array}$ & Renda fixa & Total & $\begin{array}{c}\text { Estoques } \\
\text { ações }\end{array}$ & Renda fixa \\
\hline 1991 & n.d & 8.227 & 0 & 8.227 & 4.158 & 1.207 & 2.951 \\
\hline 1992 & n.d & 3.155 & 1.120 & 2.035 & 8.441 & 1.916 & 6.526 \\
\hline 1993 & n.d & 35.266 & 4.979 & 30.287 & 43.282 & 10.257 & 33.024 \\
\hline 1994 & n.d & 9.843 & 3.116 & 6.727 & 42.043 & 10.102 & 31.941 \\
\hline 1995 & n.d & 4.734 & 1.090 & 3.643 & 50.327 & 11.597 & 38.730 \\
\hline 1996 & n.d & 12.098 & 990 & 11.108 & 66.863 & 13.730 & 53.132 \\
\hline 1997 & n.d & 11.666 & 1.391 & 10.276 & 82.209 & 19.070 & 63.140 \\
\hline 1998 & n.d & 10.693 & -210 & 10.903 & 86.298 & 14.297 & 72.001 \\
\hline $1991-1998^{(1)}$ & n.d & 95.682 & 12.478 & 83.205 & 86.298 & 14.297 & 72.001 \\
\hline 1999 & n.d & -4.780 & -10.773 & 5.993 & 83.187 & 8.389 & 74.798 \\
\hline 2000 & n.d & -1.331 & -3.227 & 1.896 & 78.437 & 3.636 & 74.802 \\
\hline 2001 & n.d & -9.715 & 31 & -9.746 & 34.265 & 2.206 & 32.059 \\
\hline 2002 & n.d & -5.117 & -116 & -5.001 & 21.794 & 862 & 20.932 \\
\hline $1999-2002^{(1)}$ & n.d & -20.943 & -14.085 & -6.859 & 21.794 & 862 & 20.932 \\
\hline 2003 & 509 & -7.663 & 65 & -7.728 & 30.456 & 2.127 & 28.329 \\
\hline 2004 & 579 & -9.358 & -86 & -9.272 & 36.200 & 2.371 & 33.829 \\
\hline 2005 & 1.125 & -1.731 & -48 & -1.683 & 33.533 & 2.496 & 31.036 \\
\hline 2006 & 171 & 7.931 & 662 & 7.270 & 44.686 & 4.377 & 40.309 \\
\hline 2007 & 60 & n.d & n.d & n.d & n.d & n.d & n.d \\
\hline $2003-2006^{(1)}$ & 2384 & -10.821 & 593 & -11.413 & 44.686 & 4.377 & 40.309 \\
\hline
\end{tabular}

Fonte: International Financial Statistics, CD-ROM; Banco Central da República Argentina.

Nota: (1) Fluxos acumulados no ano e, para os dados de estoque, valor do final de período.

A saída dos IEP iniciou-se em 1999 no caso do mercado acionário e em 2001 no de renda fixa, e somou US\$ 20 bilhões no período 1999-2001. A retração desses investimentos e das demais modalidades de fluxos de capitais (empréstimos bancários), somada aos demais choques externos que atingiram a Argentina no biênio 1998-1999, implicaram uma deterioração crescente da sua situação externa, explicitando cada vez mais a insustentabilidade do modelo (Dominguez e Tesar, 2005). ${ }^{5}$ Dada a lógica do regime de currency board vigente, essa retração provocou uma brutal contração da liquidez interna que induziu, por sua vez, um processo recessivo e deflacionário na economia argentina. Ademais, a vulnerabilidade do sistema financeiro argentino à reversão dos fluxos de capitais, intrínseca ao regime de conversibilidade, foi agravada pela predominância dos depósitos em dólares e pela concentração dos empréstimos em setores non-tradables, que amplia- 
ram a exposição das carteiras dos bancos às desvalorizações cambiais, bem como pela impossibilidade de o Banco Central atuar como emprestador em última instância nesse tipo de regime (Fanelli e Machinea, 1997; Fanelli, 2002; Cintra e Farhi, 2002).

No período após o débâcle do Regime de Conversibilidade (2003-2007), os investimentos de portfólio no mercado financeiro doméstico foram positivos em todos os anos, mas os volumes não foram muito expressivos, exceto em 2005. Os fluxos acumulados no período atingiram US\$ 2,4 bilhões. Dado o contexto de elevado apetite por risco e de search for yield em âmbito internacional vigente no período, é possível que os controles de capitais impostos após a crise tenham contribuído para desestimular esse ingresso. ${ }^{6} \mathrm{Se}$ considerarmos o total dos investimentos estrangeiros em papéis emitidos por residentes na Argentina, houve uma saída de US $\$ 10,8$ bilhões, associada ao pagamento do serviço da dívida securitizada (no valor de US\$ 11,4 bilhões); já as aplicações em ADR somaram US\$ 593 bilhões.

De acordo com os dados disponíveis, no biênio 2003-2004 o ingresso líquido desses investimentos nos dois segmentos do mercado financeiro argentino (acionário e renda fixa) continuou negativo. Certamente, a moratória da dívida externa contribuiu para esse resultado.

No México, os IEP representaram mais de $60 \%$ dos fluxos de capitais absorvidos pelo país no período que precedeu a crise cambial de dezembro de 1994 (1990-1994). O segmento do mercado financeiro mexicano mais afetado pela abertura financeira foi o mercado de títulos públicos. Em relação ao mercado acionário, os impactos dos IEP foram menos significativos, pois a maior parte das ações foi adquirida mediante ADR. Houve, assim, um vazamento da liquidez para as bolsas de valores norte-americanas, principalmente para a Bolsa de Nova Iorque.

O volume expressivo de aplicações de investidores estrangeiros em títulos públicos constitui a principal especificidade do México, em face dos outros países analisados, tanto no período pré-crise como no pós-crise. No período 1990-1994, essas aplicações corresponderam a 55\% do total dos fluxos de portfólio estrangeiros. Entre 1991 e 1993, os não-residentes absorveram a maior parte das novas emissões de títulos públicos, sobretudo as de curto prazo. Sua participação no estoque da dívida pública mexicana passou de 8\% no final de 1990 para 57\% no final de 1993 (Griffith-Jones, 1996). 
Em 1994, houve uma mudança significativa na composição da dívida pública detida pelos investidores estrangeiros. Os Cetes, títulos de curto prazo denominados em peso, foram substituídos progressivamente pelos Tesobonos, títulos de curtíssimo prazo indexados ao dólar (ver tabela 1.2). Após fevereiro desse ano, devido ao aumento da taxa de juros norte-americana e do risco cambial - associado à trajetória crescente do déficit em contacorrente -, o prêmio exigido pelos investidores estrangeiros para manterem suas posições em Cetes cresceu substancialmente. Para evitar a elevação significativa do custo de rolagem da dívida pública, assim como a saída de capitais, o governo mexicano passou a oferecer Tesobonos aos investidores não-residentes. Em conseqüência, em meados de 1994, esses investidores detinham $80 \%$ do estoque desses títulos fora do sistema bancário (Goldstein e Turner, 1996).

A experiência mexicana ilustra os efeitos negativos da abertura do mercado de títulos públicos aos investidores estrangeiros, principalmente quan-

Tabela 1.2: Os investimentos estrangeiros de portfólio no mercado de títulos públicos mexicano

\begin{tabular}{|c|c|c|c|c|c|c|c|c|c|c|c|}
\hline \multirow[t]{3}{*}{ Anos } & \multicolumn{11}{|c|}{ Títulos públicos: estoque em US\$ bilhões } \\
\hline & \multicolumn{2}{|c|}{ Cetes } & \multicolumn{2}{|c|}{ Bônus } & \multicolumn{2}{|c|}{ Tesobonos } & \multicolumn{2}{|c|}{ Ajustabonos } & \multicolumn{3}{|c|}{ Bonos de Desarrollo Total } \\
\hline & Valor & \%Total & Valor & $\%$ Total & Valor & $\%$ Total & Valor & \%Total & Valor & $\%$ Total & Total \\
\hline 1991 & 3,0 & 54,0 & n.d & n.d & 0,3 & 4,7 & n.d & n.d & n.e & n.e & 5,5 \\
\hline 1992 & 9,2 & 64,3 & n.d & n.d & 0,2 & 1,4 & n.d & n.d & n.e & n.e & 14,2 \\
\hline 1993 & 15,4 & 70,2 & n.d & n.d & 1,3 & 5,9 & n.d & n.d & n.e & n.e & 21,9 \\
\hline 1994 & 2,5 & 12,3 & - & 0,1 & 17,4 & 85,0 & 0.5 & 2,6 & n.e & n.e & 20,5 \\
\hline 1995 & 2,8 & 82,0 & 0,1 & 3,3 & 0,2 & 5,6 & 0.3 & 9,1 & n.e & n.e & 3,4 \\
\hline 1996 & 3,0 & 89,2 & 0,3 & 9,6 & 0,0 & 0,0 & - & 1,1 & n.e & n.e & 3,4 \\
\hline 1997 & 3,0 & 90,3 & 0,3 & 7,7 & 0,0 & 0,0 & - & 0,0 & n.e & n.e & 3,3 \\
\hline 1998 & 2,1 & 91,5 & 0,2 & 0,1 & 0,0 & 0,0 & - & 0,0 & n.e & n.e & 2,3 \\
\hline 1999 & 1,0 & 88,7 & 0,1 & 9,5 & 0,0 & 0,0 & - & 0,0 & n.e & n.e & 1,1 \\
\hline 2000 & 0,7 & 72,0 & 0,1 & 9,7 & 0,0 & 0,0 & 0,0 & 0,0 & 0,2 & 1,1 & 0,9 \\
\hline 2001 & 0,7 & 37,2 & 0,0 & 0,9 & 0,0 & 0,0 & 0,0 & 0,0 & 0,9 & 52,4 & 1,8 \\
\hline 2002 & 0,3 & 17,4 & 0,1 & 3,3 & 0,0 & 0,0 & 0,0 & 0,0 & 1,1 & 70,9 & 3,1 \\
\hline 2003 & 0,4 & 18,0 & 0,5 & 21,9 & 0,0 & 0,0 & 0,0 & 0,0 & 1,2 & 57,5 & 2,1 \\
\hline 2004 & 0,6 & 9,1 & 0,0 & 0,3 & 0,0 & 0,0 & 0,0 & 0,0 & 6,1 & 87,2 & 7,0 \\
\hline 2005 & 0,3 & 3,2 & 0,2 & 2,3 & 0,0 & 0,0 & 0,0 & 0,0 & 8,8 & 87,2 & 10,1 \\
\hline 2006 & 0,6 & 4,7 & 0,06 & 0,0 & 0,0 & 0,0 & 0,0 & 0,0 & 10,8 & 86,9 & 12,4 \\
\hline 2007 & 0,9 & 4,3 & 0,00 & 0,0 & 0,0 & 0,0 & 0,0 & 0,0 & 18,9 & 92,9 & 20,2 \\
\hline
\end{tabular}


do esses títulos são de curto prazo e denominados em moeda estrangeira. O mercado de Tesobonos foi um dos principais focos da crise cambial de 1994. ${ }^{7}$ A dimensão do estoque em poder de não-residentes, que superava as reservas internacionais, aumentou a vulnerabilidade do balanço de pagamentos e das contas públicas a uma possível reversão dos fluxos de capitais. Diante da crescente desconfiança em relação à capacidade do governo mexicano de honrar o pagamento desses títulos, os investidores estrangeiros passaram a vender suas posições. Como o nível de reservas era reduzido diante da dimensão da fuga de capitais, o Banco Central Mexicano não conseguiu conter a crise cambial e foi obrigado a optar pela flutuação do câmbio. Ademais, o setor público deparou com a necessidade de refinanciar um estoque elevado de dívidas de curto prazo denominadas em dólares (US\$ 9,9 bilhões venciam no primeiro trimestre de 1995), cujo valor em moeda nacional foi ampliado devido à desvalorização cambial. Assim, no caso do México, o currency mismacht no balanço financeiro do setor público fez com que a crise cambial fosse acompanhada não somente por uma crise bancária (devido às obrigações de curto prazo dos bancos denominadas em moeda estrangeira), mas também por uma crise fiscal.

Cabe ressaltar que parte significativa do aumento da dívida pública esteve associada à política monetária de esterilização parcial do ingresso de recursos externos. Ao evitar a queda da taxa de juros doméstica, essa política acabava, por sua vez, estimulando os fluxos de capitais ${ }^{8}$ (Razú, 1994). No entanto, como a dívida pública estava sendo adquirida por não-residentes, a política de esterilização não foi eficaz em reduzir a vulnerabilidade da economia e do sistema financeiro aos fluxos de capitais. Pelo contrário, essa estratégia acentuou a fragilidade externa da economia mexicana.

Após a crise cambial, os IEP no mercado de títulos públicos retraíram-se significativamente. $\mathrm{O}$ estoque de títulos detidos por não-residentes, que atingiu o valor de US\$ 20 bilhões em 1994, diminuiu de forma contínua entre 1995 e 2000. Contudo, a partir de 2001, o ingresso de recursos externos nesse mercado retomou uma trajetória crescente. Com isso, esse estoque chegou a US\$20,2 bilhões em 2007. Nessa retomada, o principal título adquirido pelos investidores estrangeiros foi uma nova modalidade instituída em janeiro de 2000, os Bonos de Desarrollo — títulos denominados em peso com um prazo maior de maturação e mais rentáveis do que os Cetes 
(Banco do México, 2005) —, cuja participação foi ascendente desde então, atingindo $92,9 \%$ em 2007.

No período 2003-2007, o governo mexicano aproveitou — assim como os governos do Chile e Brasil — o contexto de excesso de liquidez internacional vigente para trocar dívida externa, denominada em moeda estrangeira, por dívida interna, denominada em moeda doméstica (IMF, 2005; Sidaoui, 2005). A recompra antecipada de dívida externa soberana no mercado financeiro internacional foi acompanhada pelo crescimento dos IEP no mercado de dívida pública interno, estimulados pela rentabilidade elevada dos Bonos de Desarrollo.

No Brasil, no período pré-crise cambial (1990-1998), quase a totalidade dos IEP direcionou-se para a Bovespa. A captação de recursos externos mediante o Fundo de Renda Fixa Capital Estrangeiro (FRFCE) foi pouco significativa, já que esse fundo (instituído em 1993) ${ }^{9}$ captou um volume mais expressivo de recursos somente nos momentos de elevado diferencial de juros, os quais foram aplicados, principalmente, em títulos públicos indexados à taxa de câmbio, semelhantes aos Tesobonos mexicanos. Os investimentos mediante as chamadas contas CC-5 (contas de não-residentes do mercado de câmbio flutuante, extintas em 2005) ${ }^{10}$ também foram canalizados, predominantemente, para esses ativos.

Assim, nos anos 1990, os efeitos da abertura financeira concentraram-se no mercado secundário de ações. Ao contrário do México, os investimentos de portfólio no mercado acionário local foram, até 1996, mais expressivos que as aplicações em ADRs. Essa especificidade pode ser explicada pela dimensão do mercado brasileiro, que apresentava uma maior capitalização e, conseqüentemente, uma maior liquidez que o mercado mexicano. Adicionalmente, no Brasil o processo de privatização não envolveu um volume tão expressivo de ADRs como no México. Todavia, no período 1997-2002, essas aplicações superaram aquelas na Bovespa, provavelmente em função do maior risco cambial vigente nesse período devido à escassez de liquidez internacional para os países emergentes - já que esse risco não incide sobre as transações com ADRs realizadas nas bolsas de valores americanas, que não resultaram em ingresso de divisas no país.

O crescimento da participação estrangeira no total negociado na Bovespa foi acompanhado pela ampliação contínua dos volumes negociados e da 
capitalização do mercado (ver tabela 1.3). Vale mencionar que o aumento de mais de 100\% do volume de negócios entre 1996 e 1997 esteve associado às privatizações da Vale do Rio Doce e de várias empresas de energia elétrica estaduais. Os negócios também foram estimulados pelo avanço do processo de privatização dos Sistemas Telebrás e Eletrobrás.

A abertura financeira, no entanto, não contribuiu para a redução do grau de concentração do mercado secundário e para a dinamização do mercado primário de ações na década de 1990. Isso porque as aplicações dos investidores estrangeiros concentraram-se em ações de empresas estatais em processo de privatização, sobretudo da Telebrás, diante das perspectivas de valorização após a privatização. Sendo assim, o valor de mercado e a liquidez das ações das empresas privadas continuaram em patamares reduzidos, o que desestimulou a demanda dos investidores e as novas emissões. Assim, foi criado um círculo vicioso. O volume pouco expressivo de emissões primárias implicou uma redução da participação relativa das ações dessas empresas no mercado secundário, reforçando a concentração das negociações nos papéis mais líquidos (Prates, 1997).

Apesar de os investimentos de portfólio em ações (aplicações de renda variável) serem menos voláteis que as aplicações em renda fixa, devido ao maior risco de perda de capital, também implicam riscos financeiros para os

Tabela 1.3: Os investimentos de portfólio no mercado financeiro brasileiro

\begin{tabular}{lccccc}
\hline & $\begin{array}{c}\text { Estoque } \\
\text { Us } \$ \text { bilhões }\end{array}$ & $\begin{array}{c}\text { Ações } \\
\% \text { total }\end{array}$ & $\begin{array}{c}\text { Taxa fixa } \\
\% \text { total }\end{array}$ & $\begin{array}{c}\text { Debêntures } \\
\% \text { total }\end{array}$ & $\begin{array}{c}\text { Outros } \\
\% \text { total }\end{array}$ \\
\hline dez/95 & 18,6 & $89,5 \%$ & $0,0 \%$ & $5,5 \%$ & $5,0 \%$ \\
\hline dez/96 & 28,2 & $91,9 \%$ & $0,0 \%$ & $5,7 \%$ & $3,3 \%$ \\
\hline dez/97 & 35,8 & $96,5 \%$ & $0,0 \%$ & $2,1 \%$ & $1,4 \%$ \\
\hline dez/98 & 17,4 & $94,8 \%$ & $0,0 \%$ & $1,0 \%$ & $4,2 \%$ \\
\hline dez/99 & 23,1 & $98,9 \%$ & $0,0 \%$ & $0,8 \%$ & $0,1 \%$ \\
\hline dez/00 & 18,5 & $91,9 \%$ & $7,0 \%$ & $0,9 \%$ & $0,1 \%$ \\
\hline dez/01 & 15,5 & $88,5 \%$ & $9,3 \%$ & $0,7 \%$ & $1,5 \%$ \\
\hline dez/02 $/ 03$ & 10,4 & $74,7 \%$ & $21,5 \%$ & $1,2 \%$ & $2,6 \%$ \\
\hline dez/04 & 20,1 & $86,8 \%$ & $11,6 \%$ & $0,7 \%$ & $0,9 \%$ \\
\hline dez/05 & 29,0 & $90,1 \%$ & $8,3 \%$ & $0,2 \%$ & $1,4 \%$ \\
\hline dez/06 & 53,4 & $91,0 \%$ & $6,8 \%$ & $0,2 \%$ & $1,9 \%$ \\
\hline dez/07 & 101,6 & $81,7 \%$ & $16,9 \%$ & $0,3 \%$ & $1,11 \%$ \\
\hline Fonte: cvM, Informativo Mensal, vários números & $77,4 \%$ & $19,0 \%$ & $0,05 \%$ & $3,51 \%$ \\
\hline
\end{tabular}

Fonte: CVM, Informativo Mensal, vários números. 
países periféricos. Dada a grande dimensão dos fluxos de capitais em face do tamanho dos mercados acionários, os movimentos de realocação dos portfólios dos investidores estrangeiros têm fortes impactos sobre os preços das ações, que passam a apresentar maior volatilidade (Akyüz, 1992; Devlin et al., 1997). Os efeitos perversos desses movimentos sobre o mercado acionário brasileiro tornaram-se evidentes durante as crises mexicana, asiática e a própria crise cambial brasileira. Nos três momentos as cotações registraram fortes desvalorizações como conseqüência da venda de posições por parte dos investidores estrangeiros para cobrir perdas em outros mercados emergentes e/ou aumentar o caixa para fazer frente aos resgates dos cotistas.

No contexto pós-crise, os IEP retornaram ao país a partir de 2003, quando emergiu uma nova fase de excesso de liquidez internacional para os países emergentes. Entre dezembro de 2003 e dezembro de 2007, o estoque desses investimentos passou de US $\$ 20,1$ bilhões para US $\$ 214,1$ bilhões, um crescimento de 965\%, associado tanto à valorização das ações (o índice Bovespa teve alta de $187 \%$ nesse período) quanto à apreciação de $38 \%$ do real (que amplia na mesma proporção o valor em dólares do estoque de aplicações em reais).

As aquisições de ações Bovespa apresentaram uma recuperação significativa e persistente, que se intensifica a partir de 2005. Nesses anos, além do rally praticamente generalizado nos mercados acionários dos países centrais e emergentes, tanto da Ásia quanto da América Latina e Oriente Médio, esses investimentos foram atraídos pelas perspectivas de lucro com as ações negociadas no mercado doméstico (principalmente de empresas produtoras de commodities, como siderúrgicas e mineradoras) e com a apreciação da taxa de câmbio. Esses investimentos direcionaram-se para o mercado secundário - a participação dos investidores estrangeiros na Bovespa atingiu um recorde histórico em maio de 2006, de 40\%; em dezembro de 2007, essa participação era de $35,2 \%{ }^{11}$ —, bem como para o mercado primário. Os investidores estrangeiros absorveram, em média, 70\% das emissões primárias realizadas em 2006 e 2007 (respectivamente, US\$ 108 bilhões e US\$ 116 bilhões), tendo participação ativa nas ofertas públicas iniciais (Initial Public Offers - IPOs), que atingiram um número recorde nesse último ano (64 no total). ${ }^{12}$ Esse padrão foi bastante diferente do observado durante o 
ciclo de liquidez dos anos 1990, quando praticamente a totalidade das aplicações foi canalizada para o mercado secundário. Ademais, ao contrário do período 1998-2002, os investimentos de portfólio em ações no país superaram as aplicações em ADRs. Mais uma vez, é importante destacar a questão do risco cambial: após 2003, com o retorno dos fluxos de capitais para os países emergentes e a tendência de apreciação do real (associada, igualmente, à política monetária excessivamente restritiva vigente), os investidores estrangeiros buscaram usufruir os ganhos de capital decorrentes dessa tendência mediante aplicações no mercado acionário doméstico. Todavia, a concentração das transações no mercado secundário de ações continuou caracterizando essas aplicações, mesmo após a conclusão do processo de privatização.

Além da dinamização do mercado primário de ações, é importante mencionar duas características distintivas (em relação ao período pré-crise), dos IEP para o mercado financeiro brasileiro. Em primeiro lugar, o intenso crescimento das aplicações de não-residentes em títulos de renda fixa emitidos pelo governo brasileiro, em 2006, quando essas aplicações atingiram US\$ 11 bilhões em termos líquidos. Com a edição da Medida Provisória no 281, de 15.2.2006, que concedeu incentivos tributários aos investidores estrangeiros, essa modalidade de IEP apresentou uma recuperação significativa e praticamente instantânea (até então, os fluxos líquidos eram praticamente nulos). $\mathrm{O}$ estoque de investimentos estrangeiros nessa modalidade atingiu o valor recorde de US\$ 40,6 bilhões em 2007, que correspondia a 19\% do total do estoque de ativos financeiros desses investidores no país (tabela 1.3). Ou seja, essa medida revelou-se eficaz na atração dessas aplicações, no contexto de elevado apetite por risco pelos investidores estrangeiros e persistência de um diferencial ainda muito expressivo entre os juros internos e externos.

Em segundo lugar, o surgimento de uma nova modalidade de IEP, que tem a especificidade de não ser captada pela contabilidade do balanço de pagamentos, qual seja: as aplicações de não-residentes nos mercados de derivativos domésticos, permitida pela já mencionada Resolução nº 2.689, instituída na gestão Armínio Fraga Neto na presidência do Banco Central. O crescimento vertiginoso dessas aplicações - estimulado pelo anômalo diferencial entre os juros externos e internos em um contexto de ampla liquidez internacional e quedas sucessivas do risco-Brasil - foi decisivo no 
movimento de apreciação do real no período 2004-2007, já que os movimentos nos mercados futuros se transmitem ao mercado à vista devido às operações de arbitragem. ${ }^{13}$

\section{A AMPLIAÇÃo DOS INVESTIMENTOS DiRETOS ESTRANGEIROS NOS SISTEMAS FINANCEIROS}

Os mercados financeiros dos países da América Latina atraíram também, ao longo dos anos 1990, fluxos de IDE que assumiram as formas de participações acionárias em intermediários financeiros locais e de instalação de novas sucursais ou subsidiárias de controle integral de instituições financeiras estrangeiras. A intensificação das pressões concorrenciais nos mercados nacionais dos países centrais estimulou os bancos e outros tipos de intermediários financeiros a buscarem novos espaços de valorização. Em uma estratégia de fortalecimento de uma posição global e de diversificação das atividades nos mercados locais dos países anfitriões, as instituições financeiras escolheram a diversificação geográfica de suas atividades pela instalação de filiais e/ou subsidiárias em países estrangeiros.

Esse movimento foi viabilizado pela abolição ou flexibilização das restrições existentes em diversos países à instalação de filiais e de sucursais no mercado doméstico por instituições estrangeiras, à participação de não-residentes no capital social das instituições nacionais e às atividades dos intermediários financeiros estrangeiros nos mercados locais. Essas medidas de liberalização em face do tratamento conferido às instituições financeiras estrangeiras foram adotadas tanto pelos países industrializados como pelos países periféricos (Freitas, 1999).

Entre 1990 e 2003, a América Latina foi a região que mais atraiu os IED nos sistemas financeiros locais: 56\% dos fluxos destinados aos países emergentes, o que corresponde a um valor acumulado de US\$ 46 bilhões. Desse total, 50\% foram destinados ao México (CGFS, 2004, p. 5). Cabe ressaltar que, embora expressivos, os investimentos diretos nos sistemas financeiros domésticos nesse período representaram menos de 9\% do IDE total destinado à América Latina no mesmo período (US\$ 539 bilhões).

Dentre os fatores que explicam o movimento recente de entrada de importantes grupos financeiros estrangeiros, em particular europeus, na 
América Latina, se destacam a estabilização sustentada das economias latino-americanas, as perspectivas de numerosos negócios rentáveis e a predominância de competidores locais relativamente mais fracos. Os países de língua espanhola foram os primeiros alvos dos investimentos diretos de instituições financeiras estrangeiras. Na segunda metade dos anos 1990 foram a hora e vez do mercado financeiro brasileiro, bastante cobiçado por ser fonte de lucros expressivos para os bancos estrangeiros aqui já instalados.

\subsection{As estratégias de expansão dos bancos estrangeiros}

Com o propósito de diversificar suas atividades no estrangeiro, os bancos seguem diversas estratégias de expansão, adaptando-as ao quadro regulatório e legal do país anfitrião. Para os recém-chegados, a opção reside em escolher entre a instalação de uma sucursal ou uma subsidiária local com controle integral e a aquisição de participação acionária em uma instituição nacional. Já as preferências dos bancos estrangeiros já instalados recaem seja no crescimento gradual mediante a construção de uma ampla rede de agências e pela expansão da sua base de negócios, seja em uma agressiva política de compra de fatias de mercado pela absorção dos concorrentes. Essa tipologia pode ser aplicada na análise da expansão da presença das instituições bancárias estrangeiras na América Latina nos anos 1990 e na presente década.

No Brasil, algumas instituições estrangeiras optaram pela aquisição do controle acionário dos bancos locais, enquanto outras preferiram instalar sucursal ou subsidiária (tabela 2.1). No primeiro caso incluem-se o HSBC e o BBVA, que adquiriram bancos em situação falimentar. No segundo, o UBS, que instalou subsidiária de controle integral, e o Rabobank, que abriu uma sucursal.

No México, os bancos estrangeiros aproveitaram as medidas de flexibilização das condições de acesso após a grave crise financeira de 1995, adquirindo participações no capital social das instituições locais, colocadas sob controle do organismo de supervisão, a Comissão Nacional Bancária e de Valores (CNBV), e/ou financiadas pelo "Fobaproa", o fundo de garantia dos depósitos bancários. Para isso, certos bancos receberam vantagens e garantias, como foi o caso do HSBC, que assumiu 20\% do capital do banco Serfin (Martinez-Díaz, 2005, p. 19). 
M. C. P. de Freitas e D. M. Prates - Investimentos estrangeiros nos sistemas financeiros... 205

Tabela 2.1: Os principais participantes da internacionalização bancária no Brasil e no México 1995-2007

\begin{tabular}{|c|c|c|c|}
\hline $\begin{array}{l}\text { País } \\
\text { anfitrião }\end{array}$ & Instituição financeira & País de origem & Forma de entrada \\
\hline \multicolumn{4}{|l|}{ Brasil } \\
\hline & UBS & Suíça & Aquisição do Banco de Investimento Pactual \\
\hline & Société Générale & França & Aquisição do Banco Pecúnia e Banco Cacique \\
\hline & Hong Kong Shanghai & Reino Unido & Aquisição do Banco Bamerindus \\
\hline & \multicolumn{3}{|l|}{ Banking Corporation (HSBC) } \\
\hline & Groupe Crédit Suisse & Suiça & Aquisição do Banco de Investimento Garantia \\
\hline & Nations Bank & Estados Unidos & Aquisição de $51 \%$ do capital do Banco Liberal \\
\hline & United Bank of Switzerland & Suíça & Instalação de subsidiária de controle integral \\
\hline & Banco Bilbao Viscaya (BBV) & Espanha & Aquisição do Banco Excel-Econômico \\
\hline & Rabobank & Holanda & Instalação de sucursal \\
\hline \multicolumn{4}{|l|}{ México } \\
\hline & \multirow[t]{2}{*}{ Banco Bilbao Viscaya } & \multirow[t]{2}{*}{ Espanha } & Aquisição de $70 \%$ do grupo \\
\hline & & & financeiro Probursa \\
\hline & Bank of Nova Scotia & Canadá & Aquisição de $45 \%$ do capital do Banco Inverlat \\
\hline & Bank of Montreal & Canadá & Aquisição de $16 \%$ do Bancomer \\
\hline & \multirow[t]{2}{*}{ A. G. Alemania } & \multirow[t]{2}{*}{ Alemanha } & Aquisição do controle dos Bancos Banoro e \\
\hline & & & Bancrecer \\
\hline & \multirow[t]{2}{*}{ Banco Santander } & \multirow[t]{2}{*}{ Espanha } & Instalação de subsidiárias e aquisição de 51\% \\
\hline & & & do capital do Banco Mexicano \\
\hline & \multirow[t]{2}{*}{$\mathrm{HSBC}$} & \multirow[t]{2}{*}{ Reino Unido } & Aquisição de $20 \%$ do capital do grupo \\
\hline & & & financeiro Serfin \\
\hline & Banco Central & \multirow[t]{2}{*}{ Espanha } & Aquisição de $10 \%$ do capital do \\
\hline & Hispanoamericano & & grupo financeiro Prima International \\
\hline & Barclays & Reino Unido & Instalação de subsidiária \\
\hline & UBS & Suíça & Instalação de subsidiária \\
\hline & Walmart & Estados Unidos & Instalação de subsidiária bancária \\
\hline
\end{tabular}

Fontes: Freitas (1999); Freitas e Prates (2000); Martinez-Díaz (2005), Banco Central do Brasil (vários anos), Banco do México (vários anos).

No que se refere à expansão dos bancos já instalados na região (tabela 2.2), o exame do movimento recente revela que na Argentina a absorção ou a aquisição de participação majoritária nos bancos locais tornaram-se o meio preferido pelas instituições estrangeiras para reforçar suas posições no mercado local na segunda metade dos anos 1990. Alguns optaram por ampliar suas redes de agências, como o BankBoston, enquanto outros decidiram comprar bancos locais ou adquirir participações acionárias, como o BBVA, Santander e Bankers Trust. 
Tabela 2.2: Alguns exemplos da expansão dos bancos estrangeiros na Argentina, Brasil e México, 1995-2005

\begin{tabular}{|c|c|c|c|}
\hline $\begin{array}{l}\text { País } \\
\text { anfitrião }\end{array}$ & Instituição financeira & País de orig & Formas de expansão \\
\hline \multicolumn{4}{|l|}{ Argentina } \\
\hline & Hong Kong Shanghai & Reino Unido & Aquisição de $100 \%$ do Banco Roberts \\
\hline & \multicolumn{3}{|l|}{ Banking Corporation (HSBC) } \\
\hline & BankBoston & Estados Unidos & Aumento da rede de agências \\
\hline & Banco Santander & Espanha & $\begin{array}{l}\text { Aquisição de } 51 \% \text { do capital social do Banco } \\
\text { Francês do Rio de la Plata }\end{array}$ \\
\hline & Bank of Nova Scotia & Canadá & $\begin{array}{l}\text { Aumento da participação acionária de } 25 \% \\
\text { para } 100 \% \text { no capital do Banco Quilmes }\end{array}$ \\
\hline & Grupo Socimer & Suiça & Aquisição de $30 \%$ do capital do Banco Patrícios \\
\hline & Bankers Trust & Estados Unidos & $\begin{array}{l}\text { Aquisição de } 51 \% \text { do capital do Banco Liniers } \\
\text { Sudamericano }\end{array}$ \\
\hline & Crédit Agricole & França & $\begin{array}{l}\text { Aquisição de um terço do capital do } \\
\text { Banco Bisel }\end{array}$ \\
\hline & Banco Bilbao Viscaya (BBV) & Espanha & $\begin{array}{l}\text { Fusão entre o Banco Francês do Rio de la Plata, } \\
\text { controlado pelo BBV, e o Banco Credito Argentino }\end{array}$ \\
\hline \multicolumn{4}{|l|}{ Brasil } \\
\hline & Citibank & Estados Unidos & Ampliação da rede de agências \\
\hline & BankBoston & Estados Unidos & Ampliação da rede de agências \\
\hline & Banco Santander & Espanha & $\begin{array}{l}\text { Aquisição de } 51 \% \text { do capital do Banco Geral } \\
\text { do Comércio e do Banco Noroeste }\end{array}$ \\
\hline & Lloyds Bank & Reino Unido & $\begin{array}{l}\text { Aquisição do Banco Multiplic e de sua } \\
\text { financeira }\end{array}$ \\
\hline & ABN Amro Bank & Holanda & Aquisição de $40 \%$ do capital do Banco Real \\
\hline & Banco Santander & Espanha & Aquisição do Banco Bozano-Simonsen \\
\hline & Banco Santander & Espanha & $\begin{array}{l}\text { Aquisição do Banco Banespa no processo de } \\
\text { privatização dos bancos públicos estaduais }\end{array}$ \\
\hline & ABN Amro Bank & Holanda & $\begin{array}{l}\text { Aquisição do Bandepe e Paraiban no processo } \\
\text { de privatização dos bancos públicos estaduais }\end{array}$ \\
\hline \multicolumn{4}{|l|}{ México } \\
\hline & Citibank & Estados Unidos & Aquisição do Confia \\
\hline & Banco Santander & Espanha & Aquisição do Serfin \\
\hline & BBV & Espanha & Aquisição do Bancomer \\
\hline & Citibank & Estados Unidos & Aquisição do Banamex-Acivall \\
\hline & $\mathrm{HSBC}$ & Reino Unido & Aquisição do Bital \\
\hline
\end{tabular}

Fontes: Conger (1998); Freitas (1999); Clarke et al. (1999); Dages et al. (2000), Martinez-Díaz (2005).

O tratamento não discriminatório conferido ao capital estrangeiro permitiu recentemente a desnacionalização do sistema financeiro argentino. As instituições estrangeiras que durante o período de alta inflação ocupavam posições modestas no mercado local deram início, a partir de 1997, a uma série de aquisições (e de compra de participações) de bancos. Assim, no final 
da década de 1990, excetuando os dois grandes bancos públicos (Banco de la Nación e Banco de la Provincia de Buenos Aires) e uma instituição privada (Banco Galicia y Buenos Aires), os principais bancos argentinos estavam sob controle de não-residentes.

No Brasil, as estratégias de expansão agressiva dos bancos espanhóis, e também de outros rivais como o HSBC, forçaram a reação dos bancos estrangeiros já presentes no país. Alguns optaram por ampliar suas redes de agências, como os norte-americanos Citi e BankBoston, enquanto outros decidiram comprar bancos locais ou adquirir participações, como o inglês Lloyds e o holandês ABN Amro.

No México, o Citibank, único banco estrangeiro que sobreviveu à nacionalização dos anos 1980, adquiriu o Banco Confia em agosto de 1997, o qual havia sofrido intervenção do Banco Central em razão de suas atividades irregulares no exterior (The Banker, 1997, p. 46). Em 2001, o Citi aumentou sua participação no mercado bancário mexicano, comprando um dos três grandes bancos locais: o Banco Banamex-Acivall.

Os espanhóis Santander e BBV, grandes rivais em seu país de origem e na América Latina, aproveitaram o aprofundamento da abertura financeira em 1998 para ampliar suas fatias de mercado no México. O Santander adquiriu o controle do Banco Serfin, enquanto o BBV comprou o grupo financeiro Bancomer, ambos em 2000. Igualmente, o canadense Scotiabank exerceu sua opção de compra para adquirir o controle do Banco Inverlat. E, em 2002, o HSBC retornou ao mercado para comprar o Bital, o quarto maior banco mexicano à época. Em conseqüência desse movimento de expansão, atualmente a maior parte dos grandes bancos mexicanos está sob o comando estrangeiro. O sistema bancário mexicano é altamente concentrado. Em dezembro de 2007, os seis maiores bancos controlavam 82,2\% dos ativos totais do sistema financeiro. Dentre estes, havia apenas um único banco controlado por residentes, o Banco Mercantil do Norte (Banorte), quinto lugar no ranking por ativos (CNBV, 2008).

Em contraste, no Brasil, os grandes bancos privados nacionais foram bem-sucedidos em suas estratégias defensivas contra o aumento da presença estrangeira. Em particular, os dois maiores bancos, Bradesco e Itaú, realizaram diversas aquisições, comprando bancos privados menores e bancos públicos estaduais nos leilões de privatização. Esses bancos também apro- 
veitaram as oportunidades criadas pelas saídas das instituições estrangeiras que fracassaram em suas tentativas de conquistar o mercado brasileiro, como foram os casos do BBV Brasil e do America Express adquiridos pelo Bradesco, respectivamente, em 2002 e 2003, e do americano BankBoston, controlado pelo Bank of America, comprado pelo Itaú em 2005 por US\$2,5 bilhões (Balbi, 2006). O resultado dessa estratégia de conquista de parte de mercado foi a consolidação do Bradesco e do Itaú no topo da classificação dos maiores bancos privados, na qual ocupavam, respectivamente, a primeira e a segunda posição em dezembro de 2005. O maior banco estrangeiro no Brasil, o espanhol Santander, ocupava a quarta posição, atrás do brasileiro Unibanco, o qual possui participação estrangeira minoritária.

Na Argentina, a crise financeira de 2001-2002 — que se traduziu em perdas da ordem de US\$ 54 bilhões para o sistema bancário (Del Negro e Kay, 2002, p. 13) - levou vários bancos estrangeiros a se retirarem ou a reduzirem suas posições do país. ${ }^{14} \mathrm{O}$ número de bancos estrangeiros em atividade no país, que na segunda metade da década de 1990 havia crescido substancialmente, chegou a representar $44 \%$ do total das instituições bancárias em dezembro de 2000 para $31 \%$ em dezembro de 2005, passando de $39 \mathrm{em}$ 2000 para 22 em 2005, enquanto o número total de bancos caiu de 89 para 72 no mesmo período, de acordo com informações do Banco Central da Argentina.

Esse movimento abriu espaço para a reação dos bancos públicos e dos bancos privados de capital nacional, os quais se beneficiaram da perda de confiança da população nas instituições estrangeiras, as quais não ofereceram a proteção esperada pelo público por ocasião do congelamento dos depósitos em moeda estrangeira em 2001 (Lacoste, 2005, p. 93). Todavia, a retração dos bancos estrangeiros no mercado financeiro argentino se refletiu no número de bancos estrangeiros classificados no ranking das 10 maiores instituições bancárias privadas por ativo, que se reduziu de sete para cinco entre dezembro de 2001 e dezembro de 2005. Retiraram-se do mercado argentino os Bancos Scotiabank e Sudameris, que ocupavam, respectivamente, a nona e décima posições no ranking em 2001. Além disso, os estrangeiros que permaneceram perderam posição, caso do Citibank e do HSBC, que caíram, respectivamente, do quinto e sexto lugar em 2001 para o sétimo e oitavo em 2005. 


\subsection{Avaliação quantitativa da presença estrangeira nos sistemas bancários domésticos}

O resultado desse movimento recente de internacionalização sugere uma tendência de crescente importância das instituições estrangeiras nos mercados financeiros locais dos países latino-americanos analisados. Contudo, o ritmo de ampliação varia de modo expressivo de um país a outro. Como se verifica pelos dados apresentados na tabela 2.3 , no período dezembro de 1994 a dezembro de 2001, a participação estrangeira aumentou mais rapidamente no México que na Argentina e no Brasil.

$\mathrm{Na}$ Argentina, a participação dos bancos estrangeiros nos ativos totais atingiu 35\% em junho de 1997 contra 22\% no início do período. Com a intensificação da aquisição de bancos locais por não-residentes após 1997, a fatia dos estrangeiros subiu para 48,4\% em 2001. A crise de 2002 e a revisão das estratégias das instituições estrangeiras que atuavam no país explicam a expressiva queda da participação dos não-residentes observada entre 2001 e 2005 , que recuou de $48 \%$ para $26 \%$, mas voltou a subir em 2006, atingindo 27,9\% em dezembro de 2007.

Em contraste, no Brasil, o avanço dos bancos estrangeiros foi comparativamente menor e permanece modesto. A participação dos estrangeiros nos ativos totais do sistema bancário local passou de $11 \%$ a $30,1 \%$ no período considerado (1994-2001). Após 2001, os bancos estrangeiros perderam participação no mercado brasileiro. Além da redução no número, caindo de 70 em 2001 para 56 em 2006, os ativos sob controle desses bancos declinaram a 26,5\% em 2006 (30\% em 2001). Como mencionado, os dois grandes bancos privados nacionais, Bradesco e Itaú, adquiriram o controle acionário dos bancos estrangeiros que saíram do Brasil. Assim, em dezembro de 2003, a fatia dos não-residentes nos ativos totais do sistema bancário brasileiro

Tabela 2.3: Evolução de participação dos bancos estrangeiros nos sistemas financeiros nacionais

\begin{tabular}{lcccc}
\hline País & \multicolumn{4}{c}{ Ativos como \% dos ativos do sistema bancário } \\
\hline & Dez. 1994 & Dez. 1997 & Dez. 2001 & Dez. 2007 \\
\hline Brasil & 11,0 & 12,9 & 30,1 & 26,51 \\
\hline Argentina & 21,7 & 35,0 & 48,4 & 27,9 \\
\hline México & 1,2 & 13,3 & 82,0 & 83,1 \\
\hline
\end{tabular}

Fonte: Banco Central da República Argentina (vários anos), CNBV (2008); Banco Central do Brasil (vários anos); Yacamán (2001); Martinez-Díaz (2005).

Nota: Posição em dezembro de 2006. 
reduziu-se a 21\% (Prates, Freitas e Farhi, 2005). Porém, como o novo ciclo do crédito, iniciado em 2003 e que ganhou ímpeto em 2005-2006, reavivou o interesse dos bancos estrangeiros pelo mercado brasileiro, é provável que a participação estrangeira no sistema financeiro aumente nos próximos anos. O mesmo deve ocorrer se o Brasil obtiver a classificação de investment grade junto às agências internacionais de rating, dadas as inúmeras possibilidades de negócios, em particular para os bancos de investimentos (Lucchesi et al., 2007).

No México, os bancos estrangeiros controlavam mais de $82 \%$ do mercado em 2001, contra 1,2\% em 1994. No final de 2007, a participação estrangeira no sistema financeiro mexicano era de $83,1 \%$, após ter atingido $84,7 \% \mathrm{em}$ dezembro de 2005, em razão do avanço de dois bancos nacionais, o Del Bajo e o Banco Azteca, ${ }^{15}$ esse último, uma instituição bancária ativa na concessão de crédito para a população das faixas de renda C e D, criada em 2002. Esses dois bancos ocupavam em 2007, respectivamente, a nona e a décima posição no ranking, respondendo por, respectivamente, de 1,8\% e de 1,7\% dos ativos bancários totais (CNBV, 2008).

Diferenças nos aspectos institucionais das finanças de Argentina, Brasil e México certamente explicam também o maior ou o menor sucesso dos bancos estrangeiros em conquistar posições nos mercados locais desses três países. Na Argentina e no Brasil, a existência de grandes bancos públicos limita as possibilidades de expansão das instituições financeiras estrangeiras, o que não ocorre no México, onde não há mais instituições bancárias públicas.

O Brasil possui igualmente grandes bancos privados de capital nacional com forte penetração e poder de mercado que até o momento conseguiram sucesso em suas estratégias defensivas contra o avanço dos estrangeiros. Além de amplas redes de agências, os bancos brasileiros possuem tecnologias muito sofisticadas de transferência eletrônica de fundos e de gestão de recursos. Desenvolvidas no período de alta inflação, essas tecnologias os ajudaram a conservar seus clientes, impedindo a desintermediação financeira que atingiu os bancos argentinos e mexicanos. Igualmente, essas tecnologias os colocam, sobretudo no caso dos grandes bancos, para competir em condições de igualdade com os estrangeiros presentes no país.

De igual modo, em relação aos outros bancos latino-americanos, os bancos brasileiros se beneficiam do fato de que o sistema bancário nacional não atravessou nenhuma crise profunda e generalizada ao longo das últimas dé- 
cadas. Assim, no Brasil, as instituições bancárias locais não são vistas com desconfiança pelo público em geral. Ao contrário, são os bancos públicos que mais atraem clientes dos bancos privados em momentos de maior fragilidade financeira. Na Argentina, apenas após a crise financeira recente a confiança do público em instituições estrangeiras ficou menor em face dos bancos nacionais, públicos e privados.

\section{CONCLUSÕES}

Neste artigo procurou-se analisar os impactos dos investimentos estrangeiros de portfólio, bem como do aumento da participação dos bancos estrangeiros sobre os sistemas e mercados financeiros de três países latino-americanos - Argentina, México e Brasil - , nos períodos que precederam e sucederam as crises financeiras que eclodiram na segunda metade dos anos 1990.

Algumas conclusões importantes emergem da análise realizada na seção 1 sobre os investimentos estrangeiros de portfólio. Em primeiro lugar, como esperado, os graus heterogêneos de abertura financeira dos três países condicionaram os efeitos desses investimentos sobre os diferentes segmentos dos mercados financeiros domésticos. Em segundo lugar, a adoção de um menor grau de abertura, caso da economia brasileira nos anos 1990, não foi capaz de "blindá-la", evitando a eclosão de uma crise cambial. Todavia, contribuiu para reduzir a intensidade da crise e suas implicações para a economia como um todo. Isso porque, ao contrário da Argentina e do México, que enfrentaram crises gêmeas, no Brasil a crise de 1998-1999 circunscrevese ao mercado de câmbio, não tendo repercussões adversas sobre a situação financeira dos bancos e dos agentes não financeiros. Em terceiro lugar, as diferentes estratégias de liberalização dos fluxos de capitais no contexto póscrise revelam que, apesar do contexto de globalização financeira, os países emergentes ainda possuem algum grau de liberdade em relação à escolha do grau desejado de integração financeira com o exterior e, assim, ao mix de política macroeconômica.

A experiência argentina é elucidativa nesse sentido. Esse país, que possuía um grau absoluto de abertura financeira no período pré-crise e sofreu a crise financeira mais severa entre os seus congêneres latino-americanos, optou, após essa crise, pela regulação preventiva dos fluxos de capitais como 
um dos pilares do seu regime de política macroeconômica. Já o Brasil adotou o caminho oposto, pois possuía o menor grau de abertura financeira dentre os três países analisados nos anos 1990 e, no período pós-crise, aprofundou intensamente esse grau, permitindo, inclusive, o acesso dos investidores não-residentes ao mercado de derivativos financeiros domésticos.

No que se refere à abertura dos sistemas financeiros locais, constatou-se uma tendência de importância crescente das instituições estrangeiras nos mercados financeiros dos três países latino-americanos analisados na segunda metade da década de 1990, parcialmente revertida na Argentina e no Brasil no início da presente década. Essa tendência resultou, sobretudo, das medidas de liberalização adotadas pelos governos para viabilizar a capitalização dos sistemas financeiros bancários nacionais fragilizados, seja em virtude de grave crise, como no caso mexicano, seja em conseqüência do processo de adaptação ao novo contexto macroeconômico de estabilidade, como no caso brasileiro.

Igualmente, a expansão da presença estrangeira refletiu as estratégias concorrenciais dos próprios bancos, que procuram conquistar novas fontes de lucro e fortalecer suas posições em mercados cada vez mais globalizados. Submetidos à lógica concorrencial, esses bancos não se comportam necessariamente em conformidade com os propósitos das autoridades dos países anfitriões. Portanto, ao contrário do que advogam os defensores da internacionalização bancária dos países em desenvolvimento, nem sempre a forte presença de bancos estrangeiros fortalece a capacidade dos sistemas bancários domésticos de suportar os choques macroeconômicos. Também nesse caso a experiência argentina é bastante elucidativa. Após pesadas perdas em decorrência da crise cambial e financeira, vários bancos estrangeiros reviram suas estratégias e se retiraram do mercado argentino, enquanto outros reduziram suas exposições.

Cabe mencionar, ainda, que tanto na Argentina quanto no Brasil e México o volume de crédito bancário em termos do PIB permanece extremamente baixo em comparação com os países centrais e mesmo com alguns países em desenvolvimento, como os asiáticos. Ademais, nesses três países, e, em particular, no Brasil e no México, há ainda uma parte expressiva da população que não foi incorporada ao mercado de crédito e que não tem acesso aos serviços bancários. 
Igualmente, a ampliação da presença estrangeira nos sistemas bancários latino-americanos analisados, notadamente, no México e Brasil, não se traduziu em menores custos do crédito. Como destacou o presidente do Banco do México em uma conferência anual do Banco de Compensações Internacionais, “(...) os spreads bancários praticados pelos bancos estrangeiros nos países anfitriões são, em geral, muito mais altos do que os praticados em seus países de origem, a despeito de a inflação, volatilidade de mercado e impostos serem bastante similares"(Ortiz, 2006, p. 42).

\section{NOTAS}

1. Sobre as diferenças na gestão dos regimes de câmbio flutuante nos países periféricos, ver BIS (2005).

2. Esse grau diz respeito à facilidade com que os residentes podem adquirir ativos e passivos denominados em moeda estrangeira e ao acesso de não-residentes ao mercado financeiro doméstico (Akyüz, 1992).

3. Os primeiros autores consideram o currency mismatch uma conseqüência do "pecado original" (original sin), que diz respeito à incapacidade desses países de emitir dívida denominada em moeda doméstica nos mercados financeiros internacionais. O original sin estaria vinculado à estrutura do mercado financeiro internacional, especificamente aos custos de transação envolvidos na diversificação dos portfólios em âmbito global, os quais favoreceriam a aquisição de poucas moedas (principalmente daquelas emitidas por países de maior dimensão econômica) pelos investidores globais. Já Goldstein e Turner $(2004$, p. 2) atribuem o problema do currency mismatch a fragilidades internas aos países. Nas palavras desses autores: "past and present weaknesses in economic policies and institutions in emerging markets themselves rather in imperfections in international capital markets".

4. Nesse período, o Banco Central da República Argentina (BCRA) não realizava um registro desagregado desses fluxos e, assim, dos investimentos de portfólio no mercado financeiro interno. Como explicam Fanelli e Machinea (1997), grosso modo, os investimentos de portfólio correspondiam aos fluxos de capitais não especificados, que eram registrados no item "Outros Movimentos" do balanço de pagamentos.

5. Segundo Fanelli (2002), os principais choques que afetaram a balança comercial argentina foram: a desvalorização do real; a queda dos preços das exportações; a apreciação do dólar em relação ao euro; e a deterioração dos termos de troca. Para uma descrição detalhada desses choques e dos seus efeitos sobre o desempenho macroeconômico da Argentina, ver: Dominguez e Tesar, 2005.

6. Em junho de 2005, foi imposto um depósito compulsório de 30\% pelo prazo de 365 dias sobre os investimentos de portfólio no mercado financeiro doméstico, tanto em renda fixa como em renda variável (BCRA, 2007). 
7. O segundo foco da crise foi o sistema bancário, pois os bancos tinham um estoque elevado de passivos em moeda estrangeira de curto prazo, e uma parcela desses passivos tinha Tesobonos como colaterais (Griffith-Jones, 1996).

8. Além da política de esterilização, outras medidas foram acionadas para neutralizar parcialmente o impacto monetário dos fluxos, entre as quais flexibilização da política cambial, com a adoção de um regime de bandas cambiais em 1991 (Gurría, 1997).

9. O FRFCE, os demais fundos existentes e os anexos (I, II, III e IV) foram extintos pela Resolução no 2.689, de 26.1.2000, que instituiu uma nova modalidade de investimento no mercado financeiro, pela qual os investidores não-residentes têm acesso às mesmas aplicações disponíveis aos investidores residentes, inclusive ao mercado de derivativos financeiros, até então fechado a esses investidores.

10. A CC-5 foi extinta em março de 2005 pela Resolução no 3.265 , de 4.3 .2005 , que unificou os mercados de câmbio livre e flutuante.

11. Informações obtidas no site da Bovespa (www.bovespa.com.br).

12. As informações sobre o mercado primário de ações foram obtidas no Novo Informativo Mensal da Comissão de Valores Imobiliários - CVM. Disponível em: www.cvm.gov.br.

13. Sobre esses investimentos, ver: Farhi (2006).

14. Em sua maioria, eram bancos recém-chegados. Entrevistas realizadas pelo Comitê sobre Sistema Financeiro Global do BIS com instituições financeiras revelaram que a crise argentina provocou profunda alteração na percepção de risco das matrizes dos bancos em relação aos seus investimentos diretos nos sistemas financeiros dos países emergentes (CGFS, 2004, p. 17).

15. Cabe ressaltar que, em julho de 2007, o CMN aprovou voto que recomenda ao presidente Lula conceder autorização para o Azteca se instalar no Brasil sob a forma de banco múltiplo, com carteira comercial e de financiamento. Com matriz em Recife, o Azteca pretende instalar agências, em um primeiro momento, em Fortaleza e Belém. Como em seu país de origem, as agências bancárias serão mantidas dentro das lojas de sua propriedade (a Elektra). Essa estratégia possibilitou que o banco inaugurasse 800 pontos de atendimento logo no primeiro ano de operação no México (Ribeiro, 2007).

\section{REFERÊNCIAS BIBLIOGRÁFICAS}

ADAMS, C.; MATHIESON, D. J.; SCHINASI, G. International Capital Markets: developments, prospects and key policy issues. Washington DC: International Monetary Fund, jul. 1999.

AKYÜZ, Y. On financial Openness in Developing Countries. Genebra: UNCTAD, 1992.

BALBI, S. Compras recentes de bancos superam US\$ 5 bi. Folha de S. Paulo, Dinheiro, 11 de maio, 2006.

BANCO DO MÉXICO. Reporte sobre el sistema financeiro. Cidade do México: Banco do México, maio, 2006.

Informe Anual. Vários anos, Cidade do México: Banco do México. 
BANKER (The) Latin Notes: Mexican government to end bank subsidies. The Banker, Londres: Financial Times Magazine, p. 46, out. 1997.

BCB - Banco Central do Brasil. Relatório de Evolução do Sistema Financeiro Nacional. Vários anos. Disponível em http://www.bcb.gov.br, consultado em abril de 2007.

BCRA - Banco Central da República Argentina. Información de Entidades Financieras. Disponível em http://www.bcra.gov.ar, consultado em abril de 2007.

—. (2007) Comunicado n. 48699, de 5/01/2007. Disponível em http://www.bcra.gov.ar

— (2006) Comunicado n. 48633, de 2/10/2006. Disponível em http://www.bcra.gov.ar

BIS. Foreign exchange market intervention in emerging markets: motives, techniques and implications. BIS Papers, Basle: Bank of International Settlement, n. 24, 2005.

BLEJER, L.; ROZENWURCEL, G. El sistema bancario argentino en los noventa: de la profundizacion financeira a la crisis sistemica. Desarrollo Económico, Buenos Aires, v. 37, n. 146, p. 163-93, jul./set. 1997.

BOVESPA - Bolsa de Valores de São Paulo. Revista Mensal, vários números.

CALCAGNO, A. F. El régimen de convertibilidad y el sistema bancario en la Argentina, Revista de la Cepal, Santiago de Chile, n. 61, p. 63-89, 1997.

CALVO, G. A.; REINHART, C. M. When capital capital flows come to a sudden stop: consequences and policy. In: KENEN, P.; SWOBODA, A. (Ed.). Reforming the internacional monetary and financial system. Washington: Internacional Monetary Fund, 2000.

CHESNAIS, F. (Coord.). La Mondialisation Financière: genèse, coût et enjeux. Paris: Syros, 1996.

CINTRA, M. A. M.; FARHI, M. Contradicciones y límites del plano de convertibilidad. Nueva Sociedad, Caracas: Friedrich Ebert Stiftung, n. 179, p. 89-111, 2002.

CLARKE, G. et al. The effect of foreign entry on Argentina's domestic banking sector. Policy Research Working Paper. Washington, DC: The World Bank, n. 2.158. ago. 1999.

CGFS - Committee on the Global Financial System foreign investment direct in the financial sector of emerging market economies. CGFS Paper, Basle: BIS, n. 22, mar. 2004.

CNBV - Comisión Nacional Bancaria y de Valores. Boletin estadístico: bancos múltiplos. México, fev. 2008. Disponível em: http;//sidif.cnbv.gov.mx/

Boletin estadístico: grupos financieros. Mexico, dezembro. Disponível em: http;//sidif. cnbv.gov.mx/, 2006.

CONGER, Lucy Santander's Latin America crusade. Institutional Investor. Nova York: Institutional Investor Inc., p. 35-42, jan. 1998.

CRYSTAL, J.; DAGES, G.; GOLDBERG, L. Has foreign bank entry led to sounder banks in Latin America? Currents Issues in Economics and Finance, Nova York Federal Reserve Bank, v. 8, n. 1, p. 1-6, jan. 2002.

CVM - Comissão de Valores Mobiliários. Informativo Mensal, vários números.

DAGES, B.; GOLDBERG, L.; KINNEY, D. Foreign and domestic banks participation in emerging markets: lessons from Mexico and Argentina. Economic Policy Review, Nova York Federal Reserve Bank, p. 17-36, set. 2000. 
DEL NEGRO, P; KAY, S. Global bank, local crisis: bad news from Argentina. Economic Review, Federal Reserve Bank of Atlanta, Third Quarter, p. 1-18. 2002.

DEVLIN, R.; FFRENCH-DAVIS; R.; GRIFFITH-JONES, S. Fluxos de capitais e desenvolvimento: implicações para as políticas econômicas. In: FFRENCH-DAVIS, R.; GRIFFITH-JONES, S. (Org.). Os fluxos financeiros na América Latina: um desafio ao progresso. Rio de Janeiro: Paz e Terra, 1997. p. 257-283.

DOMANSKI, D. Foreign banks in emerging market economies: changing players, changing issues. BIS Quarterly Review, p. 69-81, dez. 2005.

DOMINGUEZ, K. M. E.; TESAR, L. L. International borrowing and macroeconomic performance in Argentina. Cambridge, MA.: National Bureau of Economic Research. Prepared for NBER Conference on International Capital Flows, p. 17-18, dez. 2005.

EDWARDS, S. Capital controls, sudden stops, and currency account reversals. NBER Working Paper, Cambridge, MA: National Bureau of Economic Research, n. 11.170, 2005.

EICHENGREEN, B., HAUSMANN, R.; PANIZZA, U. The mystery of original sin. In: EICHENGREEN, B.; HAUSMANN, R.; PANIZZA (Ed.). Other people's money: debt denomination and financial instability in emerging-market economies. Chicago: University of Chicago press, 2005, p. 233-265.

Currency mismatches, debt intolerance and original sin: why they are not the same and why it matters. NBER Working Paper, Cambridge, MA: National Bureau of Economic Research, n. 10.036, 2003.

FANELLI, J. M. Crecimiento, inestabilidad y crisis de la convertibilidad en Argentina. Revista de la Cepal, Santiago de Chile, n. 77, ago. 2002.

FANELLI, J. M., MACHINEA, J. O movimento de capitais na Argentina. In: FFRENCH-DAVIS, R., GRIFFITH-JONES, S. (Org.). Os fluxos financeiros na América Latina: um desafio ao progresso. Rio de Janeiro: Paz e Terra, 1997. p. 78-112.

FARHI, M. O impacto dos ciclos de liquidez no Brasil. In: CARNEIRO, R. (Org.). A supremacia dos mercados e a política econômica do governo Lula. São Paulo: Unesp, p. 173-206, 2006.

FREITAS, M. C. P. de Abertura do sistema bancário brasileiro ao capita estrangeiro In: FREITAS, M. C. P. (Org.). Abertura do sistema financeiro no Brasil nos anos 1990. São Paulo: Fundap; Fapesp; Brasília: IPEA, 1999. p. 101-173.

— Economia e Sociedade, Campinas: Unicamp - IE, n. 17, p. 81-111, 2001.

. La experiencia de apertura financiera en Argentina, Brasil y México. Revista de la Cepal, Revista de la Cepal, Santiago de Chile: Cepal, n. 70, p. 53-69, 2000.

GOLDSTEIN, M.; TURNER, P. Controlling currency mismatches in emerging markets. Washington DC: Institute for International Economics, 2004.

Banking crisis in emerging economies: origins and policy options. Basle: Bank for International Settlements. BIS Economic Paper, n. 46, out. 1996.

GRIFFITH-JONES, S. La crisis del peso mexicano. Revista de la Cepal 60, Santiago de Chile, p. 151-170, 1996. 
GURRÍA, J. A. Fluxos de capital: o caso do México. In: FFRENCH-DAVIS, R. R.; GRIFFITH-JONES, S. (Org.). Os fluxos financeiros na América Latina: um desafio ao progresso. Rio de Janeiro: Paz e Terra, 1997. p. 78-112.

HASBACH, A. P. Surgimiento y desarrollo de los grupos financeiros en México. Santiago de Chile: Comisión Económica para América Latina y el Caribe, 1997 (Serie Financiamento del Desarrollo, 41).

HAWKINS, J.; MIHALJEK D. et al. The banking industry in the emerging market economies: competition, consolidation and systemic stability. BIS Papers, Basel: Bank for International Settlement, n. 4, ago. 2006.

IMF - International Monetary Fund. Global Financial Stability. Washington, DC: International Monetary Fund, set. 2005.

- World Economic Outlook. Washington DC: International Monetary Fund, abr. 2004.

. Global Financial Stability. Washington DC: International Monetary Fund, mar. 2003.

KREGEL, J. Was there an alternative to the Brazilian crises? Brazilian Journal of Political Economy, São Paulo, v. 19, n. 3, 75, jul./set. 1999.

LACOSTE. Pedro. International capital flows in Argentina. BIS Papers, Basel: Bank for International Settlement, n. 23, p. 91-97, maio 2005.

LUCCHESI, C. et al. Avanço do crédito atraí nova leva de bancos ao país. Valor Econômico, Caderno Finanças, 15 mar. 2007.

MACHINEA, J. L. La crisis financeira Argentina de 1995: causas, características e lecciones. Buenos Aires. 1996. (mimeo.)

MARTINEZ-DÍAZ, L. (2005). Banking-sector liberalization in Mexico and Brazil: explaining the timing and style of financial opening. Paper prepared for the $10^{\text {th }}$ annual conference of Latin American and Caribbean Economic Association (LACEA), Paris, out. 2005. Disponível em http://wwwtest.aup.edu/lacea2005/system/step2_php/papers/LACEA \%20Martinez-Diaz\%20paper.pdf.

MATHIESON, D. J.; SCHINASI, G. International capital markets: developments, prospects and key policy issues. Washington DC: International Monetary Fund, jul. 2001.

MEXICO. Ley de instituciones de credito de 1990 com ementas até 30 decembro 2005. Disponível em: http://www.banxico.org.mx 2005.

MIHALJEK, D. Privatisation, consolidation and the increased role of foreign banks. In: BIS Papers. Basel: Bank for International Settlement, n. 28, p. 41-65, ago. 2006.

ORTIZ, G. Global banking: trends and policy issues: a host country perspective. BIS Paper, Basle: Bank for International Settlement, n. 32, p. 30-34, dez. 2006.

PAULA, L. F. de P. A recente onda de bancos europeus no Brasil: determinantes e impactos. São Paulo: Banco Santos, 2002.

PESCE, M. A. Banking issues in Argentina. BIS Papers, Basel: Bank for International Settlement n. 28, p. 153-162, ago. 2006. 
PRATES. Abertura financeira e vulnerabilidade externa: a economia brasileira na década de 1990. Campinas: Instituto de Economia - Universidade Estadual de Campinas, (Dissertação de Mestrado) 1997.

PRATES, D. M; FREITAS, M. C. P; FARHI. M. Internacionalização bancária e derivativos financeiros no Brasil. In: SCHERER A. (Org.). O Brasil frente à ditadura do poder financeiro: reflexões e alternativas. Univates, 2005. p. 149-172.

RAZÚ, E. C. Acceso a los mercados internacionales de capital y desarrollo de instrumentos financeiros: el caso de México. Santiago Chile: Comision Economica para America Latina y el Caribe. Serie Financiamento del Desarrollo, n. 18, jun. 1994.

RIBEIRO. Mexicano e popular, o Azteca chega ao Brasil. Valor Econômico, Caderno Finanças, n. 27, jul. 2007.

SIDAOUI, J. The Mexican financial system: reform and evolution. BIS Papers, Basel: Bank for International Settlement, n. 28, p. 277-293, ago. 2006.

. Policies for international reserve accumulation under a floating exchange rate regime: the experience of México (1995-2003). BIS Paper, n. 23 (op. cit.), 2005.

TURNER, P. et al. The banking system in emerging economies: how much progress has been made? BIS Papers, Basel: Bank for International Settlement. n. 28, ago. 2006.

YACAMÁN, J. M. Competition and consolidation in the Mexican banking industry after the 1995 crisis. BIS Papers, Basel: Bank for International Settlement, n. 4, p. 102-113, ago. 2001. 